\section{Cureus}

Received 03/11/2019

Review began 03/17/2019

Review ended 03/25/2019

Published 04/01/2019

\section{(C) Copyright 2019}

Roy. This is an open access article distributed under the terms of the

Creative Commons Attribution License CC-BY 3.0., which permits unrestricted use, distribution, and reproduction in any medium, provided the original author and source are credited.

\title{
Administration of Once-daily Canagliflozin to a Non-diabetic Patient in Addition to Standard Aerobic Exercise: A Case Report
}

Sayak Roy ${ }^{1}$

1. Internal Medicine, Calcutta Medical Research Institute Hospital, Kolkata, IND

$\square$ Corresponding author: Sayak Roy, sayak.roy.123@gmail.com

\section{Abstract}

There is no Indian data at present on sodium-glucose cotransporter 2 (SGLT2) inhibitors' role on glycated haemoglobin A1c (HbA1c), weight, and blood pressure in non-diabetic individuals. This novel mechanism of action could assure us of sustained non-glycaemic benefits along with information on the negligible risk of hypoglycaemia. The aim was to observe the changes of various parameters using canagliflozin $(300 \mathrm{mg}$ ) in a non-diabetic person suffering from hypertension and dyslipidaemia (on treatment for two years). Canagliflozin (300 mg) oncedaily was administered for 13 weeks with a continuous glucose monitoring system (CGMS) installed to assess glycaemic changes and tests done at baseline: four, eight, and 13 weeks. A dyslipidaemic and hypertensive with a family history of type 2 diabetes (T2D) (mother) and hypertension (father), the patient was currently using antihypertensive and statin therapy for two years. Over a period of 13 weeks, there was a reduction in weight by $3.2 \mathrm{~kg}$; body mass index (BMI) by $1 \mathrm{Kg} / \mathrm{m}^{2}$, visceral fat by $1.5 \%$, waist circumference by $5 \mathrm{~cm}$, uric acid level by 63.01\%, and increase in bone mineral density (BMD) (as opposed to decrease seen with SGLT2Is in other studies). There was no episode of hypoglycaemia. Our study has given rise to certain critical issues regarding the early use of canagliflozin (although on an off-label basis) in patients who are at high risk of developing diabetes in the future.

Categories: Endocrinology/Diabetes/Metabolism, Epidemiology/Public Health Keywords: canagliflozin, sglt2i

\section{Introduction}

Sodium-glucose cotransporter 2 (SGLT2) inhibitor produces transient natriuresis, diuresis, weight reduction, glycated haemoglobin $\mathrm{A} 1 \mathrm{c}(\mathrm{HbA} 1 \mathrm{c})$, and blood pressure in patients having type 2 diabetes (T2D) and also reduced cardiovascular mortality, the risk of hospitalization for heart failure, and the risk of renal events in patients with type 2 diabetes mellitus (T2DM) and those having established cardiovascular disease [1]. However, there is no Indian data to date and very rare data of SGLT2I in non-diabetics. The novel mechanism of action could assure of the negligible risk of hypoglycaemia with the sustained extra-glycemic benefits.

This case describes the effective treatment of weight loss, loss of visceral fat using Omron HBF375 (Omron Inc., Tokyo, Japan) body fat analyzer and inflammatory markers using canagliflozin (300 mg) in a non-diabetic patient suffering from hypertension and dyspilidemia (on treatment for two years).

\section{Case Presentation}




\section{Cureus}

Daily 300 mg of canagliflozin was taken by the patient from May 2018 to August 2018 over a period of 13 weeks to assess the changes with this therapy on a battery of tests as mentioned in Table 1.

\begin{tabular}{|c|c|c|c|c|c|}
\hline Name of parameter & $\begin{array}{l}\text { Baseline } \\
\text { results }\end{array}$ & $\begin{array}{l}\text { Results after } 4 \\
\text { weeks }\end{array}$ & $\begin{array}{l}\text { Results after } 8 \\
\text { weeks }\end{array}$ & $\begin{array}{l}\text { Results after } 13 \\
\text { weeks }\end{array}$ & $\begin{array}{l}\text { Results after drug } \\
\text { washout }\end{array}$ \\
\hline Hba1c (\%) & 5.8 & & & 5.8 & \\
\hline $\begin{array}{l}\text { Estimated Average } \\
\text { Glucose (mg/dl) }\end{array}$ & 120 & & & 120 & \\
\hline Creatinine (mg/dl) & 0.9 & & & 1.0 & 0.8 \\
\hline Uric Acid (mg/dl) & 7.3 & 4.2 & 5.4 & 2.7 & \\
\hline T.Cholesterol (mg/dl) & 117 & & & 103 & \\
\hline HDL (mg/dl) & 31 & & & 32 & \\
\hline LDL (mg/dl) & 52 & & & 53 & \\
\hline VLDL (mg/dl) & 34 & & & 18 & \\
\hline Tgs (mg/dl) & 271 & & & 167 & \\
\hline Hemoglobin (gm\%) & 13.5 & 13.9 & 14.3 & 14.0 & 13.4 \\
\hline Pcv (\%) & 42.9 & 43.1 & 44.2 & 42.7 & 41.3 \\
\hline EPO (miu/ml) & 14.7 & 15 & 14.4 & 13.9 & 14.0 \\
\hline APO B (mg/dl) & 68 & 64 & 60 & 65 & \\
\hline HS CRP (mg/L) & 0.8 & & & 0.67 & \\
\hline \multicolumn{6}{|l|}{$\begin{array}{l}\text { Renal doppler resistive } \\
\text { index (ri) }\end{array}$} \\
\hline Right renal artery hilum & 0.64 & 0.62 & 0.72 & 0.69 & \\
\hline Right intra-renal artery & 0.6 & 0.68 & 0.75 & 0.70 & \\
\hline Leftt renal artery hilum & 0.7 & 0.69 & 0.73 & 0.69 & \\
\hline Left intra-renal artery & 0.68 & 0.7 & 0.76 & 0.66 & \\
\hline \multicolumn{6}{|l|}{$\begin{array}{l}\text { Shear wave elastography } \\
\text { of liver (kpa) }\end{array}$} \\
\hline Average & 5.6 & & & 4.1 & \\
\hline Usg upper abdomen & $\begin{array}{l}\text { Mild fatty } \\
\text { liver }\end{array}$ & & & Mild tatty liver & \\
\hline $\mathrm{BP}(\mathrm{mm} \mathrm{Hg})$ & 110/82 & & & 108/82 & \\
\hline WEIGHT (kg) & 87.6 & 86.2 & 84.6 & 84.4 & \\
\hline
\end{tabular}




\section{Cureus}

\begin{tabular}{|c|c|c|c|c|}
\hline BMI $\left(\mathrm{kg} / \mathrm{m}^{2}\right)$ & 26.3 & 25.7 & 25.3 & 25.2 \\
\hline Total body fat $\%$ & 25.8 & 23.4 & 25.3 & 22.8 \\
\hline $\begin{array}{l}\text { Subcutaneous (sc) fat } \\
\text { whole body } \%\end{array}$ & 18.1 & 16.5 & 17.6 & 16.1 \\
\hline Sc fat trunk \% & 16.4 & 14.9 & 15.8 & 14.5 \\
\hline Sc fat arm \% & 24.6 & 21.9 & 24.4 & 21.4 \\
\hline Sc fat legs \% & 24.6 & 21.8 & 24.4 & 21.2 \\
\hline Visceral fat \% & 11 & 10 & 9.5 & 9.5 \\
\hline $\begin{array}{l}\text { Sketetal muscle (sm) } \\
\text { whole/body \% }\end{array}$ & 32.1 & 33.3 & 32.3 & 33.5 \\
\hline Sm trunk \% & 24.5 & 26.1 & 24.7 & 26.4 \\
\hline Sm arms \% & 36.5 & 37.5 & 36.9 & 37.7 \\
\hline Sm legs \% & 49.4 & 50.6 & 49.5 & 50.7 \\
\hline Body age & 47 & 44 & 45 & 44 \\
\hline Waist circumference (cms) & 101 & 99.6 & 96.52 & 96 \\
\hline \multicolumn{5}{|l|}{ Central abp } \\
\hline Central SBP & 105 & & 102 & 102 \\
\hline Pulse wave velocity & 5.3 & & 5.3 & 5.3 \\
\hline Pulse pressure & 35 & & 37 & 34 \\
\hline \multicolumn{5}{|l|}{$\mathrm{BMD} \mathrm{gm} / \mathrm{cm}^{2}$} \\
\hline Rt femur neck & 1.089 & & & 1.096 \\
\hline Lt femur neck & 1.117 & & & 1.152 \\
\hline Ls spine & 1.444 & & & .485 \\
\hline
\end{tabular}

T-score

Rt femur neck

Lt femur neck

\section{TABLE 1: Description of parameters analysed during the study}

Hba1c:glycated haemoglobin A1c; HDL:high density lipoprotein; LDL:low density lipoprotein; VLDL:very low density lipoprotein; Tgs:triglycerides test; Pcv:packed cell volume; EPO:erythropoietin; APO B:apolipoprotein B; HS CRP:high-sensitivity C-reactive protein; Usg:ultrasonography; BP:blood pressure; BMl:body mass index; abp:ambulatory blood pressure; SBP:systolic blood pressure; BMD:bone mineral density; Rt:right; Lt:left. 


\section{Cureus}

\section{Baseline drugs used}

Being a hypertensive and dyslipidemic and having a family history of T2D (mother) and hypertension (father), the patient was currently using prazosin XL (extended release) $5 \mathrm{mg}$, telmisartan $80 \mathrm{mg}$, rosuvastatin $10 \mathrm{mg}$, nevibolol $5 \mathrm{mg}$ (all taken once a day) regularly for the last two years.

\section{Drug administered}

Medtronic continuous glucose monitoring system (CGMS) (Medtronic Minimed, Northridge, CA, USA) machine was installed on 18th May and the first dose of canagliflozin $300 \mathrm{mg}$ was taken at $12 \mathrm{pm}$ on 20th May, 2018.

\section{Results}

Over a period of 13 weeks, there was a reduction in weight by $3.2 \mathrm{~kg}$, body mass index (BMI) by $1 \mathrm{Kg} / \mathrm{m} 2$, visceral fat by $1.5 \%$, waist circumference by $5 \mathrm{~cm}$, uric acid level by $63.01 \%$, and mild increase in bone mineral density (BMD) as seen in Figure 1 (as opposed to decrease seen with SGLT2Is in other studies). There was no hypoglycaemia (Figure 2).
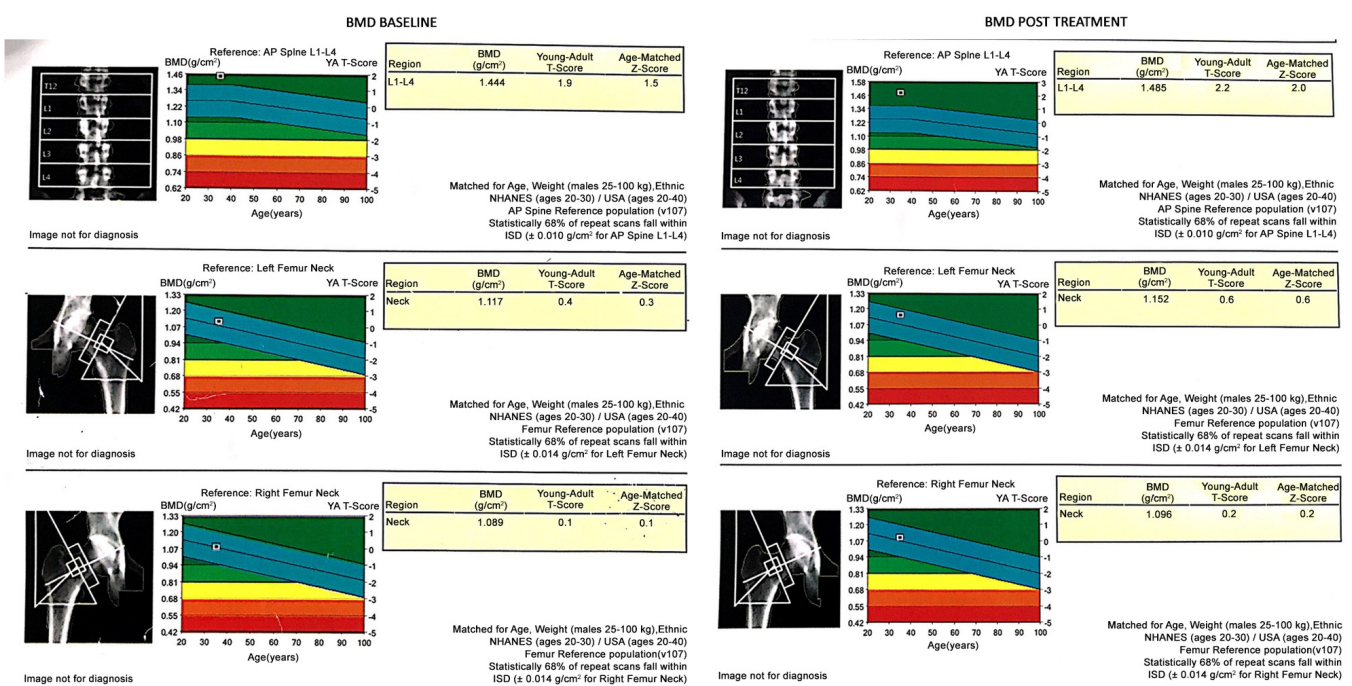

FIGURE 1: Bone mineral density (BMD) at baseline and on 13th week 


\section{Cureus}

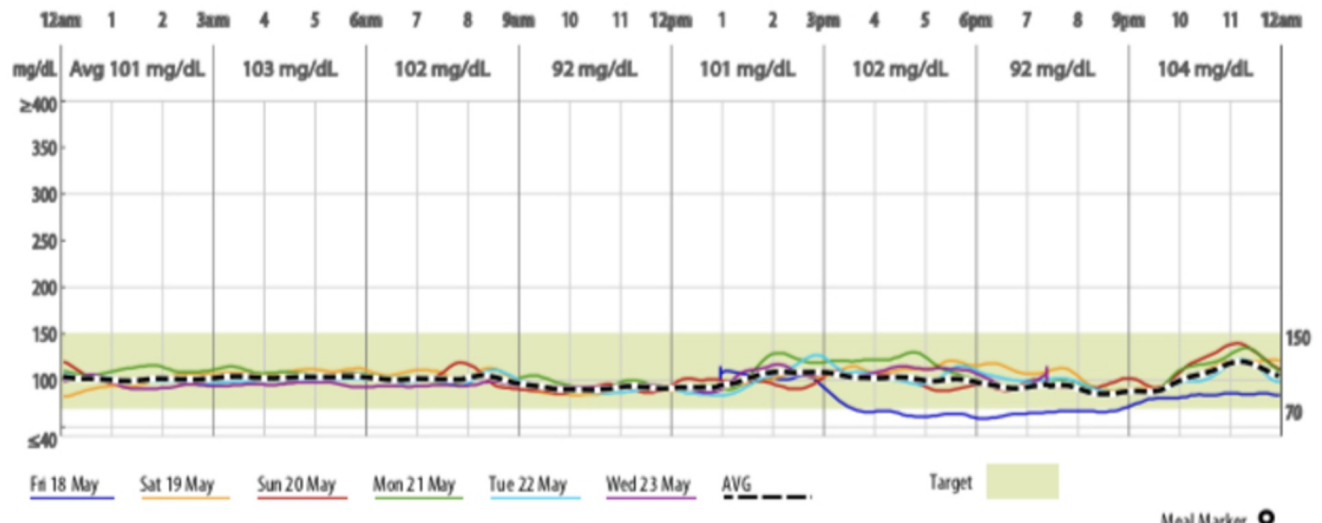

FIGURE 2: Continuous glucose monitoring system data assessed over 13 weeks

There was also a small drop in erythropoietin level at the end of the study (as opposed to a rise seen with SGLT2Is on T2DM in other small studies) [2]. There was no change in the fundal scan as measured by the Carl Zeiss (Visuscout 10, Zeiss, Jena, Germany) machine (Figure 3). Sleeping time (7 hours) ABPM showed a decreased trend during the drug intake period when compared with ABPM reading after 10 days of drug washout period (Table 2).

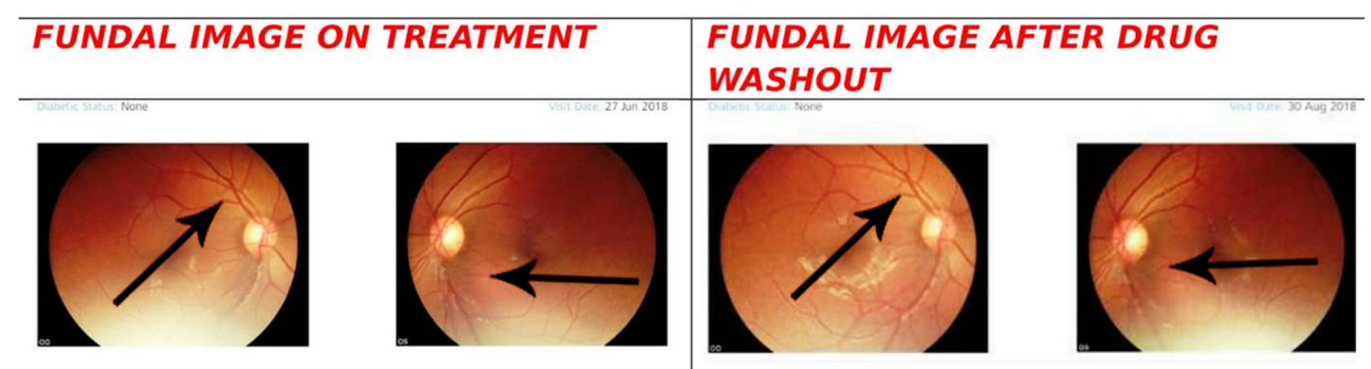

FIGURE 3: Fundal scan after one month of therapy and 10 days after drug wash out period

\begin{tabular}{|c|c|c|c|c|c|}
\hline Measurement done & AVG SBP & AVG DBP & AVG pulse rate & AVG mean arterial pressure & AVG pulse pressure \\
\hline On treatment & 101.6 & 60.3 & 71 & 69.8 & 41.33 \\
\hline After drug washout & 103.7 & 74.0 & 62.44 & 76.33 & 36.88 \\
\hline
\end{tabular}

\section{TABLE 2: Changes in sleeping (seven hours) ambulatory blood pressure monitoring} (ABPM)

Avg: average; SBP: systolic blood pressure; DBP: diastolic blood pressure. 


\section{Discussion}

There was also a small drop in erythropoietin level at the end of the study (as opposed to a rise seen with SGLT2Is on T2DM in other small studies) [2]. There was no change in the fundal scan as measured by Carl Zeiss - Visuscout 100 machine (Figure 3). Sleeping time (seven hours) ABPM showed a decreased trend during the drug intake period when compared with ABPM reading after 10 days of drug washout period (Table 2).

SGLT2Is have shown multiple modes of action to bring out the cardiovascular and renal benefits without causing dyselectrolytemia [3] or any serious adverse events in most of the cases. They have also shown to reduce visceral fat and increase skeletal muscle trunk [4]. Canagliflozin has provided clinically significant body-weight reductions as well as reductions in HbA1c and SBP [5] in diabetics but data in non-diabetics is insufficient. Our study showed a reduction in weight, BMI and waist circumference over the 13 weeks period.

Taking into consideration the genotypical predisposition of Asians to high cardiovascular disease (CVD) burden, the World Health Organization (WHO) expert panel has set $22.9 \mathrm{~kg} / \mathrm{m} 2$ as the upper cut-off value of BMI for Asians [6].

Fracture risk in CANVAS trial (Trial number NCT01032629) was increased in patients having:

- Increased age with a previous history or having a risk of CVD or

· Having lower estimated glomerular filtration rate at baseline or

- Having more baseline diuretic use

Fractures occurred more at non-vertebral sites (at upper extremities) [7]. However, there was no increase in fracture risk in our study (instead there was a small rise in BMD), though the duration of exposure could be considered less.

The reduction of uric acid reduction by SGLT2Is has been attributed to the increased glucose delivery to distal tubules where GLUT9 absorbs that in exchange of uric acid. This action seems to persist in non-diabetics as well [7].

Increased Hematocrit level in EMPAREG outcome (Trial number NCT01131676) has been attributed to be a major cardiovascular benefit contributing factor [8]. Recently Sano et al. have proposed that the increase in erythropoietin (EPO) levels with SGLT2Is could be due to the recruitment of neural-crest-derived fibroblasts producing EPO which stops getting converted to myofibroblasts due to the reduction in proximal tubular oxygen consumption [9]. Another proposed mechanism is hypoxia at the level of corticomedullary junction due to afferent arteriolar constriction by SGLT2Is. In this case, we saw a declining trend of EPO with time which reverted back (incompletely) on stoppage of the drug. This is a new finding as SGLT2I by virtue of their afferent arteriolar vasoconstriction should actually increase in the initial stage followed by maintenance of the previous level of EPO but we found a decreasing trend, the reason of which needs to be further clarified in large scale trials.

\section{Conclusions}

This experimental case has given rise to certain critical issues regarding the early use of canagliflozin and SGLT2Is (although on an off-label basis) in patients who are having a high risk of developing diabetes in the future. A personalized approach in specific populations is the need of the hour to control the diabetes epidemic. The persistence of these extra-glycemic 
benefits in non-diabetics might open up a new horizon for research with these molecules in patients of polycystic ovarian disease, nonalcoholic fatty liver disease/nonalcoholic steatohepatitis (NAFLD/NASH) where weight loss is the core-stone of therapy.

\section{Additional Information \\ Disclosures}

Human subjects: Consent was obtained by all participants in this study. Conflicts of interest: In compliance with the ICMJE uniform disclosure form, all authors declare the following:

Payment/services info: All authors have declared that no financial support was received from any organization for the submitted work. Financial relationships: All authors have declared that they have no financial relationships at present or within the previous three years with any organizations that might have an interest in the submitted work. Other relationships: All authors have declared that there are no other relationships or activities that could appear to have influenced the submitted work.

\section{Acknowledgements}

- I would like to acknowledge the contribution of Dr. Parvan A Shetty (MBBS, MD, DNB, DM), Super-Specialty Medical Officer (SSMO), Dept. of Clinical Pharmacology, Seth G.S. Medical College \& KEM Hospital, Mumbai, Maharashtra, India, in editing this manuscript. • I would like to acknowledge the contribution of Dr. AbhijnanGhosh (MBBS, MD-PGT, Department of Pharmacology, IPGMER, Kolkata, INDIA) in addressing my health-related issues during this study period.

\section{References}

1. Hsia DS, Grove O, Cefalu WT: An update on sodium-glucose co-transporter-2 inhibitors for the treatment of diabetes mellitus. Curr Opin Endocrinol Diabetes Obes. 2017, 24:73-79.

2. Lambers Heerspink HJ, de Zeeuw D, Wie L, Leslie B, List J: Dapagliflozin a glucose-regulating drug with diuretic properties in subjects with type 2 diabetes. Diabetes Obes Metab. 2013, $15: 853-62$.

3. Roy S: Retrospective study of electrolytes change with concomitant usage of SGLT2I and diuretics in T2DM patients. Indian J Appl Res. 2018, 8:68-73.

4. Roy S: Retrospective, observational, non-interventional analysis of non-glycemic parameters with SGLT2I on type 2 diabetes mellitus patients stable on OADs. Indian J Appl Res. 2018, 8:63-67.

5. Cefalu WT, Stenlöf K, Leiter LA: Effects of canagliflozin on body weight and relationship to HbA1c and blood pressure changes in patients with type 2 diabetes. Diabetologia. 2015, 58:1183-7. 10.1007/s00125-015-3547-2

6. Lim JU, Lee JH, Kim JS, et al.: Comparison of World Health Organization and Asia-Pacific body mass index classifications in COPD patients. Int J Chron Obstruct Pulmon Dis. 2017, 12:24652475 .

7. Watts NB, Bilezikian JP, Usiskin K, Edwards R, Desai M, Law G, Meininger G: Effects of canagliflozin on fracture risk in patients with type 2 diabetes mellitus. J Clin Endocrinol Metabol. 2016, 101:157-166.

8. Inzucchi SE, Zinman B, Fitchett D, et al.: How does empagliflozin reduce cardiovascular mortality? Insights from a mediation analysis of the EMPA-REG OUTCOME Trial. Diabetes Care. 2018, 41:356-363. 10.2337/dc17-1096

9. Sano M, Takei M, Shiraishi Y, Suzuki Y: Increased hematocrit during sodium-glucose cotransporter 2 inhibitor therapy indicates recovery of tubulointerstitial function in diabetic kidneys. J Clin Med Res. 2016, 8:844-847. 10.14740\%2Fjocmr2760w 